\title{
The Application of Database Analytic Hierarchy Process (AHP) in Teacher-to-Teacher Assessment
}

\author{
Fu Jinghong ${ }^{\mathrm{a}}$,Wu Yan ${ }^{\mathrm{b}}$, Yan Hongcan ${ }^{\mathrm{a}}$ \\ ${ }^{a}$ College of Science Hebei United University Tangshan, Hebei, China \\ ${ }^{b}$ College of Foreign Language Hebei United University Tangshan, Hebei, China
}

\begin{abstract}
By studying the simulated process of teacher-to-teacher assessment, the article elaborates on the scientificity and objectiveness of the application of AHP in assessing teachers' comprehensive working performance. Through computer programming, AHP is put into practice in the field of scientifically assessing teachers' working performance. Furthermore, it argues for the application of database in managing and assessing data as well as computer software in evaluating and calculating. This software also is applicable to other kinds of multiple-objective decision-making and assessing.
\end{abstract}

Index Terms: Teacher-to-teacher assessment; database; Analytic Hierarchy Process (AHP); eigenvector

(C) 2013 Published by MECS Publisher. Selection and/or peer review under responsibility of the International Conference on E-Business System and Education Technology

\section{INTRODUCTION}

Recent years, the scale of higher education has been continuously enlarged, resulting in relatively laggard teaching environment, which has to some extent influenced the quality of education. Education quality is the lifeblood of colleges. Therefore, much concern must be given to the factors relating to the improvement of education quality. These factors involve both hardware and software, of which the former includes teachers, teaching and experimenting devices, the application of modern education methods, etc., the latter includes education beliefs, teaching administration, discipline construction, courses and textbooks, etc. Among all of the factors, quality of teacher is a crucial factor.

It has become a common phenomenon at colleges that professors are not willing to give lectures and lecturers are not able to lecture. Among those state colleges, the professors not giving lecture can account for about one third and associate professors about one fifth. Some unqualified professors are called "stereotyped

professors", for they are sometimes looking up at the ceiling, sometimes looking at the blackboard, sometimes looking down at the floor, but seldom do they keep eye contact with students. Moreover, some

\footnotetext{
* Corresponding author:

E-mail address: ${ }^{1}$ Fujinghong111@126.com
} 
young teachers are not devoted to their jobs, and lack responsibility. A set of teaching assessment system can be effective and necessary in improving the quality of education.

Usually, teacher-to-teacher assessment is operated by some leaders or colleagues, the result of which depends on teaching experience and interpersonal relationships, lacking in scientificity and persuasiveness. Teacher-to-teacher assessment is a matter of multiple-objective assessment, which consists of three essentials: assessor, assessment index and assessing methods. To ensure the fairness in the process of teacher-to-teacher assessment, group assessment as well as scientific assessment index should be adopted. Only by this, can the result of teacher-to-teacher assessment work effectively in promoting teachers' working enthusiasm and improving the quality of education.

\section{The Critical Technology of the application AHP in Teacher-to-Teacher Assessment}

AHP approach is based on the theory of sequencing, in the process of which the results of assessment can be put into the order from the highest mark to the lowest. Decision is made depends on the sequenced order. To be specific, this process can be illustrated like this: firstly, the matter to be solved is considered to be a system influenced by multiple elements. Those elements are inter-related and inter-acted. They are ranked from the top to the bottom according to the administrative affiliation, which is defined as hierarchic structure. Next, these elements are put into an order by the experts, scholars and authorities, using mathematic methods. Finally, the sequenced order is analyzed and applied to the process of decision-making.

The defining feature of AHP is that it combines both qualitative and quantitative analysis. It converts the qualitative data into quantitative data; therefore, it fits into more complicated situations in the field of social studies, and ensures the accuracy. Besides, though it has a profound theoretical foundation, its application is simple and easy to understand, so this approach has been widely used in practice.

\section{A. Constructing Teacher-to-teacher Hierarchic Structure}

Index system (as is shown in mathematical model-Figure 1) is constructed as follows after a thorough analysis on teacher-assessment at colleges.

Index 1(B1): (Teacher-qualification) includes education, academic degree, professional ranks, etc.. In addition, it also refers to teachers work and the completion of assigned tasks.

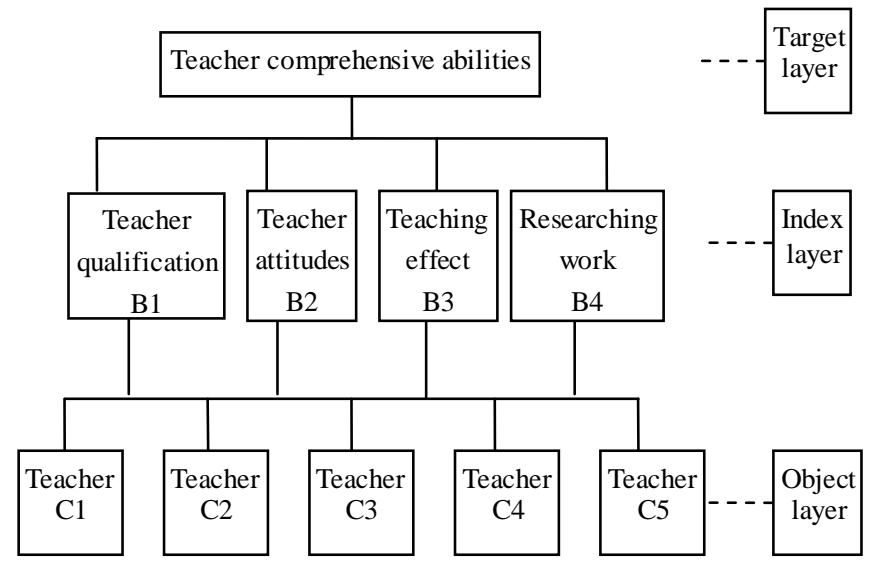

Figure 1 Constructing Teacher-to-teacher Hierarchic Structure 
Index 2(B2): (Teaching attitudes) refers to teachers' devotion and attitudes towards teaching, including how well the lessons are prepared, whether the teacher provides on-time tutoring for students, and whether the teacher is able to guide students in both professional knowledge and morals, etc.

Index 3(B3): (Teaching effect) mainly refers to classroom teaching. including focused teaching, ell designed electronic teaching plan, refined language, moderate rate of speech, proper information input, etc.

Index 4(B4): (Researching work) mainly refers to teachers' researching work in teaching practice and science, including teacher-as-master research projects, teacher-as-main-participant research projects, papers, awards, etc.

\section{B. Judgment Matrices of Each Layer in Hierarchic Structure and Their Weight}

This procedure is the core of AHP, which consists of three steps: first, calculate the weight of index layer to target layer, next the weight of each index, finally the overall weight of each teacher. Assessment results depend on the sequencing result.

- Assessing the Weight of Each element of Index Layer

The average mark of experts' marks on the weight of each index and Saaty theory are served as the basis for the constructing of Judgment Matrices of Index Layer to Target Layer.

Table 1 Judgment Matrices of Layer 2 to Layer 1

\begin{tabular}{|l|l|l|l|l|}
\hline A-B & B1 & B2 & B3 & B4 \\
\hline B1 & 1 & 2 & 2 & 1 \\
\hline B2 & & 1 & 2 & 1 \\
\hline B3 & & & 1 & 1 \\
\hline B4 & & & & 1 \\
\hline
\end{tabular}

According to Table 2, $\mathrm{RI}=0.90, \mathrm{CR}=\mathrm{CI} / \mathrm{RI}=0.022<0.1$, the correspondence of Judgment Matrices can be acceptable.

Table 2 RI numer by Saaty

\begin{tabular}{|l|ccccccccc|}
\hline $\mathbf{n}$ & $\mathbf{1}$ & $\mathbf{2}$ & $\mathbf{3}$ & $\mathbf{4}$ & $\mathbf{5}$ & $\mathbf{6}$ & $\mathbf{7}$ & $\mathbf{8}$ & $\mathbf{9}$ \\
\hline $\mathbf{R I}$ & 0 & 0 & 0.58 & 0.90 & 1.12 & 1.24 & 1.32 & 1.41 & 1.45 \\
\hline
\end{tabular}

So the weight of teacher-qualification, teaching attitudes, teaching effect and researching work are respectively(398, 0.236, 0.167, 0.199).

- Assessing the Weight of Each Element in the Object Layer

Firstly, calculate the average mark of each teacher. Based on the average marks, construct the Judgment Matrices of the Index Layer to the Target Layer which is shown in table 3, table 4, table 5, table 6.

Table 3 Judgment Matrices of the third layer to Index 1

\begin{tabular}{|l|l|l|l|l|l|}
\hline B1-C & C1 & C2 & C3 & C4 & C5 \\
\hline C1 & 1 & 2 & $1 / 2$ & 1 & 3 \\
\hline C2 & & 1 & $1 / 2$ & 1 & 2 \\
\hline C3 & & & 1 & 3 & 5 \\
\hline C4 & & & & 1 & 2 \\
\hline C5 & & & & & 1 \\
\hline
\end{tabular}


Calculate the maximum eigenvector $\mathrm{W}=(0.217,0.151,0.395,0.160,0.077)$, the maximum eigenvalue $\lambda \max =5.015 \mathrm{CI}=0.017, \mathrm{CR}=0.015<0.1$. If correspondence test is acceptable, the scores of the top five teachers in teacher-qualification can be got.

Table 4 Judgment of the third Layer to Index 2

\begin{tabular}{|l|l|l|l|l|l|}
\hline B2-C & C1 & C2 & C3 & C4 & C5 \\
\hline C1 & 1 & 5 & 3 & 1 & 5 \\
\hline C2 & & 1 & $1 / 3$ & $1 / 4$ & 1 \\
\hline C3 & & & 1 & $1 / 2$ & 3 \\
\hline C4 & & & & 1 & 5 \\
\hline C5 & & & & & 1 \\
\hline
\end{tabular}

Calculate the maximum eigenvector $\mathrm{W}=(0.370,0.069,0.169,0.326,0.066)$, the maximum eigenvalue $\lambda \max =5.018 \mathrm{CI}=0.012, \mathrm{CR}=0.011<0.1$. If correspondence test is acceptable, the scores of the top five teachers in teaching attitudes can be got.

Table 5 Judgment Matrices of the third Layer to Index 3

\begin{tabular}{|l|l|l|l|l|l|}
\hline B3-C & C1 & C2 & C3 & C4 & C5 \\
\hline C1 & 1 & 7 & 4 & 2 & 6 \\
\hline C2 & & 1 & $1 / 4$ & $1 / 5$ & $1 / 3$ \\
\hline C3 & & & 1 & $1 / 3$ & 3 \\
\hline C4 & & & & 1 & $1 / 2$ \\
\hline C5 & & & & & 1 \\
\hline
\end{tabular}

Calculate the maximum eigenvector $\mathrm{W}=(0.439,0.044,0.161,0.271,0.085)$, the maximum eigenvalue $\lambda$ max $=5$. $186 \mathrm{CI}=0.047, \mathrm{CR}=0.042<0.1$. If correspondence test is acceptable, the scores of the top five teachers in teaching effect can be got.

Table 6 Judgment Matrices of the third Layer to Index 4

\begin{tabular}{|l|l|l|l|l|l|}
\hline B4-C & C1 & C2 & C3 & C4 & C5 \\
\hline C1 & 1 & $1 / 3$ & $1 / 2$ & $1 / 3$ & $1 / 3$ \\
\hline C2 & & 1 & 2 & 1 & 1 \\
\hline C3 & & & 1 & $1 / 2$ & $1 / 2$ \\
\hline C4 & & & & 1 & 1 \\
\hline C5 & & & & & 1 \\
\hline
\end{tabular}

Calculate the maximum eigenvector $\mathrm{W}=(0.082,0.260,0.138,0.260,0.260)$, the maximum eigenvalue $\lambda \max =5.010 \mathrm{CI}=0.002, \mathrm{CR}=0.002<0.1$. If correspondence test is acceptable, the scores of the top five teachers' in researching work can be got. 


\section{Algorithm implementation of AHP based on Database}

AHP is in relation to a wealth of complicated mathematical calculating, which needs computer aid. Through the powerful calculating ability of computer, the assessment index data can be stored and managed in database in advance. Then through computer programming, the process of AHP can be realized, hence achieving the goal of scientific assessment of teacher's working performance.

\section{A. The Managing and Maintaining of Assessment Data}

In consideration to the scalability and practical features of assessment software, we propose the idea of making use of Access database to store and manage assessment data, the reasons are as follows:

By storing the assessment data in advance, it facilitates to revise and perfect. Besides, it avoids the calculating mistakes made by wrong input.

In consideration of scalability, users are able to apply it to other assessment cases by using the software and establishing index system, which has in fact enlarged the objects of the assessment software.

Data are maintained by database, which facilitates users' inquiries and calculating.

Data-based AHP software calculating process is shown in Figure 2.

Figure 2 the Flow Chart

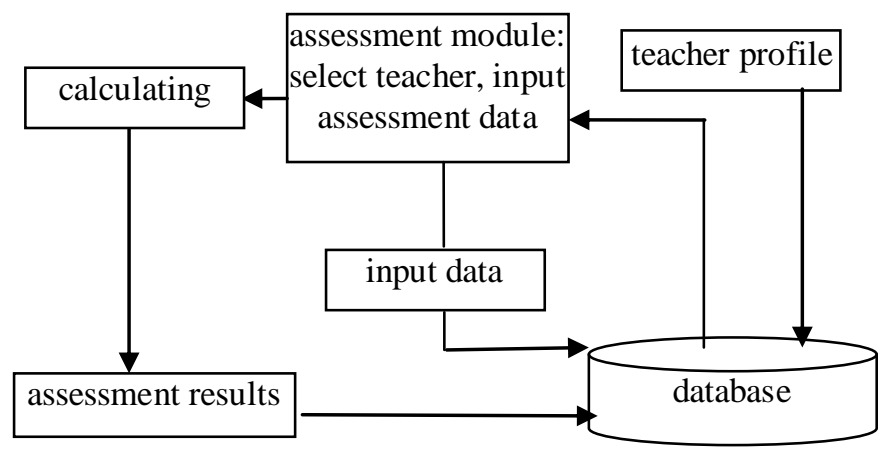

\section{B. Computer Programmed}

The core calculating approaches on computer is mainly referred to Matrix Multiplication and Matrix Iteration, etc.

' function name: MMul

Functions: calculating Matrix Multiplication

Sub MMul(n As Integer, $\operatorname{mtxA}()$ As Double, $\operatorname{mtxB}()$ As Double, $\operatorname{mtxC}()$ As Double)

Dim i As Integer, $\mathrm{j}$ As Integer

For $\mathrm{i}=1$ To $\mathrm{n}$

$\operatorname{mtxC}(i)=0$

For $\mathrm{j}=1$ To $n$

$\operatorname{mtxC}(i)=m t x C(i)+\operatorname{mtx} A(i, j) * m t x B(j)$

Next $j$

Next $i$

End Sub

'Function name: MEigenv

Functions: calculating Matrix Maximum eigenvalue

Sub MEigenv(n As Integer, m As Integer, Lmx As Double, mtxA() As Double, mtxC() As Double)

'initialization $\mathrm{X}(0)$

For $\mathrm{k}=1$ To $\mathrm{n}$ 
$\operatorname{mtxB} 1(\mathrm{k})=1$

Next k

$\operatorname{mtxA} 1()=\operatorname{mtxA}()$

'Through Power Iteration, it is referred that $\mathrm{X}(\mathrm{k})=\mathrm{mtxC} 1(), \mathrm{X}(\mathrm{k}+1)=\mathrm{mtxB} 1()$

For $\mathrm{i}=1$ To $\mathrm{m}$

Call MMul(n, mtxA1(), mtxB1(), mtxC2())

For $\mathrm{j}=1$ To $\mathrm{n}$

$m t x C 1(j)=m t x B 1(j)$

$\operatorname{mtxB} 1(\mathrm{j})=\operatorname{mtxC} 2(\mathrm{j})$

Next j

Next i

Dim 1 As Integer, $p$ As Integer

For $\mathrm{p}=1$ To $\mathrm{n}$

$\operatorname{Lm} 1(\mathrm{p})=\operatorname{mtxB} 1(\mathrm{p}) / \operatorname{mtxC} 1(\mathrm{p})$

Next $\mathrm{p}$

Call $\operatorname{Mmax}(\mathrm{n}, \operatorname{Lmx}, \operatorname{Lm} 1())$

For $1=1$ To $n$

$\operatorname{mtxC}(1)=\operatorname{mtxC} 1(1)$

Next 1

End Sub

'Function name: Mmax

'Function: compute the maximum of a set of numbers.

Sub Mmax(n As Integer, max As Double, mtxA() As Double)

Dim i As Integer, $\mathrm{j}$ As Integer, $\mathrm{k}$ As Integer, $\mathrm{p}$ As Integer

For $\mathrm{p}=1$ To $\mathrm{n}$

If $\operatorname{mtxA}(\mathrm{p})<0$ Then

$\operatorname{mtxA}(\mathrm{p})=0-\operatorname{mtxA}(\mathrm{p})$

End If

Next $\mathrm{p}$

For $\mathrm{i}=1$ To $\mathrm{n}$

$\mathrm{k}=0$

'Compare

For $\mathrm{j}=1$ To $n$

If $\operatorname{mtxA}(\mathrm{i})>=\operatorname{mtxA}(\mathrm{j})$ Then

$\mathrm{k}=\mathrm{k}+1$

End If

Next $\mathrm{j}$

If $\mathrm{k}=\mathrm{n}$ Then

' $\mathrm{m}=\mathrm{i}$

$\max =\operatorname{mtxA}(\mathrm{i})$

End If

Next i

End Sub

In practice, the maximum of Matrix can be computed by using MEigenv function.

\section{Implementing the Program}

The program is developed based on VB.Net, Access database. Its major functions include: input teacher profile, setting assessment index, AHP assessing, assessment results inquiry, etc. It also supports in theory, that is $\mathrm{N}$ teachers assessment. Because the adding of each teacher may have a great influence on the amount of calculating, too many teachers in assessing will influence the calculating efficiency. Moreover, the assessing 
data can be stored by the software, and input in groups separately. And it also prevents input data from unnecessary loss due to unexpected interrupt.

\section{Conclusion}

The maximum eigenvector and eigenvalue in the above teacher-to-teacher assessment are processed by the software, the accuracy of which has reached the demand of assessment. This software can be applicable to any cases of assessment with multiple objectives.

\section{References}

[1] Goh, C.H. Analytic hierarchy process for robot selection[J]. Journal of Manufacturing Systems, 1997, 16 (5), 381-386.

[2] G. C. Roper-Lowe; J. A. Sharp. The Analytic Hierarchy Process and Its Application to an Information Technology Decision[J]. The Journal of the Operational Research Society, Vol. 41, No. 1. (Jan., 1990), pp. 49-59.

[3] Zilla Sinuany-Stern. Ranking of Sports Teams via the AHP[J]. The Journal of the Operational Research Society, Vol. 39, No. 7. (Jul., 1988), pp. 661-667.

[4] Saaty TL. Multicriteria Decision Making-The Analytic Hierarchy Process-Planning, Priority Setting, Resource Allocation[M]. RWS Publications: Pittsburgh, USA. 1990.

[5] Labib, A., O'Connor, R. and Williams, G. An intelligent maintenance model (system): an application of AHP and a fuzzy logic rulebased controller[J]. Proceedings of the First European Conference on Intelligent Management Systems in Operations, University of Salford, 25-26 March, pp. 87-98. 1997. 